\title{
Designing the selenium and bladder cancer trial (SELEBLAT), a phase III randomized chemoprevention study with selenium on recurrence of bladder cancer in Belgium
}

Maria E Goossens ${ }^{1,2^{*}}$, Frank Buntinx ${ }^{1,3}$, Steven Joniau ${ }^{4}$, Koen Ackaert $^{5}$, Filip Ameye ${ }^{6}$, Ignace Billiet ${ }^{7}$, Johan Braeckman ${ }^{8}$, Alex Breugelmans ${ }^{9}$, Jochen Darras ${ }^{10}$, Kurt Dilen ${ }^{11}$, Lieven Goeman ${ }^{12}$, Eliane Kellen ${ }^{13}$, Bertrand Tombal ${ }^{14}$, Siska Van Bruwaene ${ }^{4}$, Ben Van Cleyenbreuge ${ }^{4}$, Frank Van der Aa ${ }^{4}$, Kris Vekemans ${ }^{10}$, Hendrik Van Poppel ${ }^{4}$ and Maurice P Zeegers ${ }^{2,3}$

\begin{abstract}
Background: In Belgium, bladder cancer is the fifth most common cancer in males (5.2\%) and the sixth most frequent cause of death from cancer in males (3.8\%). Previous epidemiological studies have consistently reported that selenium concentrations were inversely associated with the risk of bladder cancer. This suggests that selenium may also be suitable for chemoprevention of recurrence.

Method: The SELEBLAT study opened in September 2009 and is still recruiting all patients with non-invasive transitional cell carcinoma of the bladder on TURB operation in 15 Belgian hospitals. Recruitment progress can be monitored live at http://www.seleblat.org. Patients are randomly assigned to selenium yeast (200 $\mu \mathrm{g} /$ day) supplementation for 3 years or matching placebo, in addition to standard care. The objective is to determine the effect of selenium on the recurrence of bladder cancer. Randomization is stratified by treatment centre. A computerized algorithm randomly assigns the patients to a treatment arm. All study personnel and participants are blinded to treatment assignment for the duration of the study.
\end{abstract}

Design: The SELEnium and BLAdder cancer Trial (SELEBLAT) is a phase III randomized, placebo-controlled, academic, double-blind superior trial.

Discussion: This is the first report on a selenium randomized trial in bladder cancer patients.

Trial registration: ClinicalTrials.gov identifier: NCT00729287

Keywords: Selenium, Bladder cancer, Transitional Cell Carcinoma, Chemoprevention, Randomized clinical trial, Urology

\section{Introduction}

In Belgium, 2159 patients were newly diagnosed with a primary bladder cancer in 2008. These numbers have been stable over the last five years. The incidence and mortality rates increase sharply with age and about two-thirds of patients are $\geq 65$ years old. The mean age of diagnosis is

\footnotetext{
* Correspondence: Mieke.Goossens@med.kuleuven.be 'Department of General Practice, University of Leuven, ACHG-KU Leuven, Kapucijnenvoer 33, Blok J, bus 7001, 3000 Leuven, Belgium Full list of author information is available at the end of the article
}

73 years for men and 74 years for women. In the age group 45-59 years, the male/female ratio is $3: 3$, while in the age group 60-74 years the incidence rates in males are more than fivefold than the rates in females. The relative 5 -year survival is $47 \%$ for men and $54 \%$ for women [1]. Almost 400,000 bladder cancer cases occurred worldwide in 2008 [2]. Moreover, in the USA and probably in most Western countries, bladder cancer is the most expensive cancer in terms of healthcare expenditure [3] because of lifetime ongoing cystoscopies. Any reduction in the need

\section{C) Biomed Central}


for cystoscopies reduces the cost and even more important, improves quality of life.

Evidence supporting the use of selenium as a general cancer preventive agent includes proof from geographical, animal, in vitro, epidemiological and intervention studies. High selenium intake in Venezuela is associated with a reduced cancer risk [4]. In animal models, antitumourigenic activity has been observed for metabolites of naturally occurring forms of selenium such as selenomethionine, selenocysteine and methylselenocysteine and inorganic selenium salts, such as selenite and selenate $[5,6]$. Recent in vitro studies have demonstrated that selenium may be an effective chemopreventive and anticancer agent with a broad spectrum against several human cancer cells (prostate, colon, bladder, lung, liver, ovarian, leukemia). In total, twenty-eight different selenium compounds have been reported to have anticancer, chemopreventive or apoptotic activities [7-9]. Three case-control studies reported an increased risk of bladder cancer, associated with lower serum [10] and toenail [10-12] selenium concentrations. A meta-analysis of bladder cancer incidence in five observational studies [13-17] found an inverse association with an overall risk estimate of 0.67 (95\% CI 0.46 to 0.97 ) suggesting a protective effect of higher selenium levels against bladder cancer [18]. The Nutritional Prevention of Cancer (NPC) study from Clark in 1996 was the first intervention study that showed a decrease in the incidence of prostate, lung and colorectal cancers in the selenium-supplemented group of older Americans. The effect seemed to be the strongest in the individuals with the lowest selenium status $(<123.2 \mathrm{ng} / \mathrm{mL})[19,20]$. Nevertheless, not all cancer prevention trials indicated reduced cancer risk by selenium supplementation. The selenium and Vitamin E Cancer Prevention Trial (SELECT) failed to show a benefit of selenium supplementation in reducing the risk of prostate cancer in a population of healthy men [21]. The lack of positive effect of selenium supplementation on the prostate cancer incidence observed in this study may have been due to the different form of selenium used, selenomethionine, compared to Se-enriched yeast in the NPC study [8,22].

The review of Brinkman et al. [23] and the later studies of Grossman et al. [24], Altwein et al. [25], Busby et al. [26] and Amaral et al. [27] suggest that selenium may be suitable for chemoprevention as well as for treatment. It is useful to perform a selenium trial in a country such as Belgium where the selenium intake is low due to low soil selenium content. In the Belgian case control study the mean blood selenium level in the cases was $78.77 \mathrm{ng} / \mathrm{mL}$ compared with $92.31 \mathrm{ng} / \mathrm{mL}$ in the controls [10]. This contrasts with the patients enrolled in the NPC and the SELECT trials who had higher initial plasma levels of selenium (113 ng/mL and $135 \mathrm{ng} / \mathrm{mL}$, respectively) [28] and an intake of approximately $90 \mu \mathrm{g} /$ day. As selenium is mainly excreted in the urine, it comes into direct contact and has prolonged exposure with the bladder mucosa, making the role as a potential chemoprevention agent biologically plausible, unlike the case in prostate cancer.

The objective of SELEBLAT is to investigate whether $200 \mu \mathrm{g} /$ day Selenium-yeast, in addition to standard care, reduces the risk of recurrence for patients with noninvasive bladder cancer.

\section{Methods}

\section{Clinical design}

SELEBLAT is a phase III randomized, double-blind, placebo-controlled, multicentre, academic trial with $200 \mu \mathrm{g} /$ day Selenium-yeast supplementation during 3 years with a subsequent follow-up period of 3 years aimed at the prevention of recurrence of non-muscle-invasive bladder cancer (NMIBC). SELEBLAT was initiated by the Department of General Practice of the University of Leuven and the Department of Urology of the University hospitals of Leuven, Belgium with funding by the Agency for Innovation by Science and Technology Belgium (IWT).

\section{Outcome}

The primary endpoint of SELEBLAT is the recurrencefree interval defined as the time from the date of trial entry to the date of recurrence in patients with superficial transitional cell carcinoma of the bladder. A recurrence is defined as the new occurrence of a bladder cancer at the same or at a different site as the index cancer and excluding tumours identified at the first cystoscopy at three month. Tumours identified within the first three months are considered as incompletely resected primary tumours in patients who were macroscopically tumour-free after the first resection.

A secondary endpoint is the progression-free interval defined as the time from the date of trial entry to the date of progression. Progression is defined as a recurrence with an increase in tumour grade from low grade (G1-G2) to high grade (G3), or an increase in TNM stage, or a new occurrence of carcinoma in situ (CIS) in the bladder previously free from such lesions, or a new occurrence of multiple tumours following resection of a solitary tumour, or the need for a cystectomy because of refractory disease.

\section{Eligibility criteria for participants}

Men and women, at least 18 years of age, who give informed consent, are eligible for inclusion in SELEBLAT, if they have undergone a transurethral resection (TUR) of a histologically confirmed transitional cell carcinoma of the bladder, stage pTa, pT1 or Carcinoma in situ (Cis). Primary and second primary tumours are included. Eligibility and exclusion criteria are:

- Men and women, aged above 18 years

- Histologically confirmed non-muscle-invasive transitional cell carcinoma (< pT2): stage pTa, pT1 or Carcinoma in situ (Cis) 
- Primary and second primary tumours

- Able to be randomized within three months after transurethral resection of the bladder tumour

- Must be able to swallow pills

- Must agree not to take supplements containing selenium, apart from the trial medication

- Fertile female patients must use effective contraception

- No invasive or metastatic disease (stage pT2 or above)

- No history of any type of malignancy within the past five years

- No other serious medical or psychiatric illness that would preclude giving informed consent

- No known hypersensitivity or adverse reactions to selenium

- Not taking more than $50 \mathrm{mg}$ selenium/day as a dietary supplement, including multivitamin supplements within the last 30 days

- Not concurrently participating or having participated in any other clinical trial involving a medical, surgical, nutritional or life-style intervention (unless no longer receiving the intervention and being in the follow-up phase)

\section{Participant recruitment}

Patients are recruited by the participating urologists of 15 hospitals throughout Belgium (Flanders and Brussels) from September 2009 to August 2012. All subjects have to master the Dutch or French language and may be excluded due to illness, mental sickness or incapacity to comprehend the questions as evaluated by the treating clinician. Eligible patients receive oral and written information (information brochure) from the research nurse and sign an informed consent form. The procedures followed are in accordance with the ethical standards of the responsible committee on human experimentation (institutional and national) and with the Helsinki Declaration of 1975 , as revised in 2008 . The study has been approved by the ethical review board of the University Hospital of Leuven acting as the central ethical review board, by the trial steering committee and by the appropriate ethical review boards related to the hospitals in which it is performed. A Data Safety Monitoring Board (DSMB), comprised of individuals with expertise in the areas of medicine and biostatistics, has been established to serve as an external review committee to monitor the progress of the study including accrual and adverse events.

\section{Randomization}

Randomization is stratified by treatment centre. Once a patient is deemed to be eligible for the trial and has given written consent, a trained research nurse randomizes the patient by using the database. A computerized algorithm randomly assigns the patients to a treatment arm. All study personnel and participants are blinded to treatment assignment for the duration of the study. To evaluate patient blinding, patients are asked by a questionnaire to evaluate which treatment they believe they have received (selenium, placebo, or don't know). If patients answer either selenium or placebo, they are asked to indicate what led to that belief.

\section{Participant follow-up}

Study participants are supplied with the study drug and followed on a bi-annual basis for a period of up to three years. This follow-up phase entails questionnaire distribution and monitoring for adverse events. Study questionnaires capture the onset of new illnesses and symptoms, including potential selenium-related toxicities.

\section{Investigational medicinal product (IMP)}

The active product is selenium $(200 \mu \mathrm{g} /$ day, in the form of high-selenium yeast, SelenoPrecise from PharmaNord, Vojens, Denmark). A six-month intake of $200 \mu \mathrm{g}$ of SelenoPrecise yeast increases the plasma selenium levels on average from a baseline value of (mean \pm SD) $92 \pm$ $20 \mathrm{ng} / \mathrm{mL}$ to $196 \pm 42 \mathrm{ng} / \mathrm{mL}$. The increase of the plasma selenium level is dose-dependent [29]. Patients in each study arm received an oral tablet (selenium or placebo) to be taken daily, in addition to standard care. Standard care is provided as described by Oosterlinck in the "Guidelines on diagnosis and treatment of superficial bladder cancer" [30]. Placebos have been manufactured to be identical in appearance, smell and taste to the active agents. They were identical in their composition except for the active agents. The duration of the treatment in both arms is three years, in absence of concurrent illness that prevents further administration of treatment, an unacceptable adverse event, an unacceptable toxicity or if a patient decides to withdraw from the study. Treatment stops if general or specific changes in the patient's condition render the patient ineligible for further treatment in the judgment of the investigator or the treating physician.

\section{Drug interactions/precautions}

There are no known contra-indications, interactions or precautions for the use of selenium. A few individuals are allergic to yeast for whom this form of supplement would clearly be unsuitable, but this is not a common problem [19]. Known adverse health effects of selenium concern the synthesis of thyroid hormones (diminished T3 level), hepatotoxicity, gastrointestinal disturbances, nail and hair loss and dermatitis. However these symptoms have been associated with selenium intakes of more than $700 \mu \mathrm{g}$ a day [31].

\section{Safety and toxicity}

Data on toxicity of selenium yeast are available from two animal studies while a number of human 
intervention studies show that the chronic administration of Se-yeast up to $800 \mu \mathrm{g} / \mathrm{d}$ provides no evidence of toxicity [19].

In 2008 there was an outbreak of selenium toxicity (selenosis). The source was identified as a liquid dietary supplement that contained 200 times the labelled concentration of selenium in the form of sodium selenite. Of 201 cases identified in ten states in the US, one person was hospitalized. The median estimated dose of selenium consumed was $41749 \mu \mathrm{g} /$ day. Frequently reported symptoms included diarrhoea (78\%), fatigue (75\%), hair loss $(72 \%)$, joint pain $(70 \%)$, nail discoloration or brittleness (61\%), and nausea (58\%) [32]. It is suggested that hair, fingernails and toenails may all act as excretory organs when excess amounts of selenium are ingested [33]. The Food and Nutrition Board-Institute of Medicine [34] fixed the highest daily level of selenium that is likely to pose no risk of adverse health effects in almost all individuals at $400 \mu \mathrm{g}$ selenium per day [31].

\section{Compliance and drug accountability}

The message of compliance is repeated during each follow-up visit. Patients are encouraged to return unused medication and empty packs. In order to check compliance, the research nurse counts and records the remaining unused tablets during each follow-up visit. Unused medication is collected and destroyed by PharmaNord.

\section{Data collection}

Patients receive a self-completion questionnaire after TUR, comprising questions about socio-demographics (age, sex, ethnicity, marital status, education) healthrelated lifestyle (lifetime smoking, history, passive smoking), medical and drug history, dietary intake (food-type frequency, alcohol, caffeine and total fluid intake, use of vitamins), social support and quality of life. The qualityof-life questions were developed by the European Organization for Research and Treatment for Cancer (EORTC). Assessments using the general cancer questionnaire QLQ-C30 and the QLQ-BLS24, with 24 supplemental questions, are made at baseline, after 6 and 36 months. A full version of the baseline and the follow-up questionnaires is available as a free download at http://www.bcpp.bham.ac.uk/seleblateng/patients.shtml. Patients' medical records are regularly examined by the research nurses for information on clinical treatment, histopathology, and outcome measures, which are reported on case report forms.

Blood samples are collected at baseline. A research nurse collects blood from all patients in a 5-mL EDTA tube for selenium measurement and one plain $10-\mathrm{mL}$ tube for DNA-analysis. After the three-year intervention period a new blood sample for selenium measurement is collected.

\section{Adverse event and serious adverse event monitoring strategy}

For the purpose of this trial, any detrimental change in the patient's condition subsequent to the start of trial treatment and during the trial follow-up period, which is not unequivocally due to the underlying disease process of bladder cancer, is considered as either an adverse event ( $\mathrm{AE})$ or a serious adverse event (SAE). Adverse events and serious adverse events are being monitored during and between regular follow-up visits in accordance with the legal regulations.

\section{Statistical analysis}

Final statistical analysis is on an intention-to-treat basis. Kaplan-Meier estimates of a recurrence-free interval are used to compare treatment groups descriptively, whilst log-rank tests are used to test the hypothesis of no difference between treatments. Cox proportional hazards regression models are used to estimate the Hazard risks and 95\% confidence intervals comparing patients randomized to active selenium versus placebo with and without adjustment for age, sex and stage at time of diagnosis. A per protocol analysis will be performed as a sensitivity analysis. We will also test for interactions with possible additional effect modifiers such as smoking, selenium at baseline as an indicator of selenium intake. For secondary outcome measures, treatment arms are compared in terms of progression-free interval using Kaplan-Meier and logrank tests. The reasons for excluding patients from the analysis are clearly reported.

All analyzes are performed using STATA (StataCorp. 2009. Stata Statistical Software: Release 11. College Station, TX: StataCorp LP)

\section{Sample size calculations}

Sample size calculations are based on the recent metaanalysis $(\mathrm{N}=2820)$ by Malström et al. [35] who looked at the recurrence after standard treatment (instillations of mitomycine or BCG). This is the group that corresponds best with our placebo-group (standard care). The absolute difference between the placebo- and the Selenium-group is based on the difference in percent of recurrence after five years (average of time after randomization in our study). A difference of $12,5 \%$ in absolute reduction can be expected, considering that the intake of $200 \mu \mathrm{g}$ of SelenoPrecise yeast increases the plasma selenium by $\pm 100 \mathrm{ng} / \mathrm{mL}$ [29] and that, according to epidemiological studies, the incidence of bladder cancer decreases by $25 \%$ if the plasma selenium increases by 10 $\mathrm{ng} / \mathrm{mL}[10]$.

To detect an absolute decrease of $12,5 \%$ in the recurrence-free rate by selenium versus placebo, 700 patients are needed, taking into account a drop out of $25 \%$ with a power of $86 \%$ (two-sided test). 


\section{Interim analyses}

An independent data and safety monitoring board will periodically review the efficacy and safety data. Two formal interim analyses of efficacy will be performed as soon as the first 100 patients have reached one and two years after randomization. The interim analyses will enable the study to be stopped early if a clear result should emerge. This will take place if a statistically significant increase or decrease in recurrence rate of at least $10 \%$ has been found.

\section{Baseline characteristics}

At the time of writing we have recruited 177 patients. After one year of recruitment, 137 patients were assessed for eligibility of which 100 met the inclusion criteria. All patients were between 46 and 88 years and their mean age was $68( \pm 9)$ years. Eighty-three percent of the patients were male and $87 \%$ of them Dutchspeaking. Sixty percent had a primary tumour and $60 \%$ had a solitary tumour. Seventy-nine percent of the tumours were papillary. The baseline plasma selenium was $84.8 \mathrm{ng} / \mathrm{mL}( \pm 18.5 \mathrm{ng} / \mathrm{mL})$. Baseline characteristics were summarized in Table 1.

\section{Discussion}

This is the first report of a trial in tertiary prevention of selenium for bladder cancer. Other chemopreventive trials have been performed [24,36]. High dose vitamins improved significantly the time to tumour recurrence ( $p$ $=0.0014$ ) [37]. Retinoids have been tested with various results [38-40]. Neither vitamin B6 (Pyridoxine) [41,42] nor difluoromethylornithine reduced the rate of recurrence [43]. Lactobacillus casei powder significantly reduced the time to recurrence in the intervention group $[44,45]$. Several ongoing trials are investigating cyclooxygenase- 2 inhibitors in the recurrence of bladder cancer. Preliminary analysis of the results of the study based at the MD Anderson Cancer Center did not demonstrate a difference in time to tumour recurrence between the two treatment arms [24]. We are aware of one other selenium and vitamin E factorial trial (SELENIB) that is currently recruiting in the UK [46]. This chemoprevention study, which is largerly similar to our study (as far as the selenium arm is concerned), aims to include 500 patients with non muscle-invasive bladder cancer. In this trial, patients receive a daily supplement of $200 \mu \mathrm{g}$ high selenium yeast or placebo and $154 \mathrm{mg}$ daily $\alpha$-tocopherol or placebo for 5 years using a $2 \times 2$ factorial design. Two chemopreventive trials on prostate cancer with selenium yeast are currently ongoing [47].

Selenized yeast was selected for use in this trial because of its availability and well-characterized safety profile. In both the SELECT trial (prostate cancer prevention) and the NPC trial (basal cell or squamous cell skin cancer prevention), selenium supplementation was
Table 1 Baseline characteristics of randomized participants in the SELEBLAT trial

\begin{tabular}{|c|c|c|c|}
\hline \multicolumn{2}{|l|}{ Variable } & \multicolumn{2}{|c|}{ Total 100} \\
\hline Gender [N (\%)] & Male $[\mathrm{N}(\%)]$ & 83 & (83) \\
\hline & Female & 17 & $(17)$ \\
\hline \multirow[t]{6}{*}{ Age } & $\leq 50 \mathrm{yrs} .[\mathrm{N}(\%)]$ & 2 & $(2)$ \\
\hline & $51-60$ [N (\%)] & 17 & $(17)$ \\
\hline & 61-70 [N (\%)] & 34 & (34) \\
\hline & $71-80$ [N (\%)] & 36 & (36) \\
\hline & $>80[\mathrm{~N}(\%)]$ & 11 & $(11)$ \\
\hline & Years [mean, (SD)] & 68 & (9) \\
\hline \multirow[t]{2}{*}{ Language [N (\%)] } & Dutch & 87 & $(87)$ \\
\hline & French & 13 & (13) \\
\hline Primary & Primary & 61 & $(60)$ \\
\hline \multirow[t]{2}{*}{ Tumour [N (\%)] } & Recurrent & 35 & (35) \\
\hline & Unknown & 5 & (5) \\
\hline Tumour & G1 & 31 & (30) \\
\hline \multirow[t]{3}{*}{ Grade [N (\%)] } & G2 & 35 & (34) \\
\hline & G3 & 33 & $(32)$ \\
\hline & Unknown & 4 & $(4)$ \\
\hline Tumour & pTa & 60 & (58) \\
\hline \multirow[t]{3}{*}{ Stage [N (\%)] } & pT1 & 31 & (30) \\
\hline & Cis & 5 & (5) \\
\hline & Unknown & 7 & (7) \\
\hline Tumour & Papillary & 121 & (79) \\
\hline \multirow[t]{2}{*}{ Type [N (\%)] } & Cis & 29 & (19) \\
\hline & Unknown & 3 & (2) \\
\hline Tumour & $<1 \mathrm{~cm}$ & 59 & (38) \\
\hline \multirow[t]{2}{*}{ Size $[N(\%)]$} & $\geq 1$ and $\leq 3$ & 56 & (37) \\
\hline & $>3 \mathrm{~cm}$ & 38 & $(25)$ \\
\hline Tumour & Solitary & 59 & $(60)$ \\
\hline \multirow[t]{2}{*}{ Number [N (\%)] } & 2 or more & 36 & (36) \\
\hline & Unknown & 4 & $(4)$ \\
\hline Selenium & $\mathrm{ng} / \mathrm{mL}$ [mean, (SD)] & 84.8 & $(18.5)$ \\
\hline
\end{tabular}

not significantly associated with any of the cardiovascular disease endpoints during 7.6 years of follow-up (all cardiovascular diseases, myocardial infarction, stroke, all cardiovascular disease mortality) [48]. In secondary analyses of data from the NPC study, 58 subjects in the selenium-supplemented group $(\mathrm{n}=600)$ and 39 subjects in the placebo group $(\mathrm{n}=602)$ developed type 2 diabetes (hazard ratio 1.55 ; 95\% CI, 1.03-2.33) [49]. In the SELECT trial a statistically non-significant increased risk of type 2 diabetes was observed in the selenium group (RR, 1.07; 99\% CI, 0.94-1.22) but not in the selenium vitamin E group [21]. A secondary analysis was carried out using data from a pre-existing randomized clinical trial designed to investigate the effects of selenium yeast on prostate cancer progression (Watchful Waiting Trial) [50]. There were no statistically significant differences in glucose levels during the course of the trial in men supplemented with selenium as compared with those on 
placebo. Laclaustra et al. reports that in U.S. adults, high serum selenium concentrations were associated with higher prevalence of diabetes and higher fasting plasma glucose and glycosylated hemoglobin levels. Mean serum selenium level in this trial was $137.1 \mathrm{ng} / \mathrm{mL}$ [51]. In the New England case-control study, independently of the selenium serum level, an increase bladder cancer risk was associated with a history of diabetes (adjusted odds ratio $=2.2,95 \% \mathrm{CI}, 1.3$ to 3.8 ). The risk may be greater among patients taking oral hypoglycemics and those with diabetes of longer duration [52]. Total cholesterol, triglycerides, LDL cholesterol, and fasting serum glucose concentrations significantly increased with serum selenium concentration in the Taiwanese elderly. The mean serum selenium concentration was $89.76 \mathrm{ng} / \mathrm{mL}$ [53]. In the UK, the PRECISE Pilot trial randomized 501 elderly volunteers of relatively low selenium status [mean (SD) plasma selenium 88.8 (19.2 ng/ $\mathrm{mL})$ ] to a six-month treatment with 100, 200 or $300 \mathrm{mg}$ selenium/day as high-selenium yeast or placebo yeast [36]. Supplementation at 100 and $200 \mathrm{mg}$ selenium/day lowered total serum cholesterol and non-HDL cholesterol [54]. The effects of a long-term selenium supplement on blood pressure are inconsistent. Laclaustra et al. reported that blood pressure increases if the plasma selenium level is higher than $160 \mathrm{ng} / \mathrm{mL}$ [55]. In a cross-sectional study with selenium in Belgium, the Flemish Study on Environment Genes and Health Outcomes (FLEMENGHO), $20 \mathrm{ng} / \mathrm{mL}$ higher plasma selenium level was associated with a clinically not relevant lower blood pressure with an effect sizes of $2.2 \mathrm{mmHg}$ systolic (95\% CI -0.57 to $-5.05 ; \mathrm{p}=0.009$ ) and 1.5 $\mathrm{mmHg}$ diastolic (95\% CI -0.56 to $-2.44 ; \mathrm{p}=0.017$ ) in men, but not in women [56]. As in Belgium the daily intake of selenium is low, we think that patients taking selenium for three years can only benefit from this treatment, including of blood pressure reduction.

If it is possible to increase the time to recurrence with selenium, patients have to undergo fewer cystopscopies. This means a reduction not only in suffering for the patient, but also in costs for society.

We are aware that the selenium status at baseline and the genetic variation of tested individuals may represent additional reasons for positive or negative results [8] or risk of disease [54]. There are 25 selenoproteins and three selenium-containing enzymes (glutathione peroxidases, thioredoxin reductases and iodothyronine deiodinases), the first two being linked with antioxidant activity, and the latter involved with thyroid hormone metabolism. Rayman [57] suggests that only those persons at risk, those with single nucleotide polymorphisms in selenoproteins, GPx1, GPx4, SEPS1, Sep15, SEPP1 and TXNRD1, should be treated with selenium at doses which optimize the plasma selenium levels in order to activate specific selenoproteins. An intake of $40 \mu \mathrm{g}$ per day is required to maintain the plasma glutathione peroxidase (GPx) activity at plateau [58]. We will be investigating those additional genetic analyses in a subsequent sub-project.

The SELEBLAT study is well-designed. Selenium-yeast is a safe and cheap medicine. A computerized program performs our randomization. Neither the investigators, nor the research nurses have access to the randomization numbers. All study personnel is blinded for the medication. Both treatment groups are regularly compared on similarity of prognostic characteristics such as age, gender, smoking, grade of tumour, baseline selenium level and co-morbidity. We will report reasons and numbers of those patients lost to follow up. Both an intention to treat and a per protocol analysis will be performed. For hypothesis building subgroup analyses and analyses of interactions will be performed, as we have demographic and clinical data and questionnaires results on diet and Quality of Life. Standard treatment will be compared between the intervention and the placebo group. Additional intake of selenium by food supplements will be analyzed and compliance will be reported. Our primary outcome measures are both clinical and histologically confirmed recurrences as frequently patients with clinical recurrence are only cauterized without taking a biopsy. Cauterization only reduces the risk of perforation of the bladder. All subsequent patients undergoing TUR operation are included meeting the inclusion criteria. We decided to include both primary and second primary tumours, because the incidence of bladder cancer is low, while the prevalence and the rate of tumour recurrence is high [24]. Recurrence within the first three months after TUR is considered as residual untreated disease. Although bladder cancer and prostate cancer occur together in $10 \%$ of the cases $[59,60]$, we decided to exclude patients with prostate cancer too. We deliberately did not exclude any patient for presence of co-morbidity or age aiming for a study population, which represents as far as possible the normal population diagnosed with bladder cancer. We intend to reach the calculated sample size by pooling of our results with the results from the Selenib study (UK), which is similar in design. Progress of the study can be followed on the website: http://www.genepid.bham.ac. uk/Seleblat_Recruitment.shtml. The first results of our study can be expected for 2014 .

\section{Acknowledgements}

With thanks to all participating urologists from the 15 recruiting hospitals for their continued support: Peter Dekuyper, Henri Minnaert, Guy Renders, Karl Lessage, Pieter Verleyen, Peter Vossaert, Patrick Werbrouck, Dirk Michielsen, Brigitte Winnepenninckx, Pieter Mattelaer, Diederik Ponette, Dirk Herremans, Peter Martens, Jo Stragier, Koen Van Renterghem, Patrick Willemen, Hubert Claes, Benoit Hermans, Jolanda Verheezen, Koen Ackaert, Christophe Ghysel, 
Dieter Ost and Hans Goethuys. We would also like to recognize the invaluable contribution made by the research nurses: An Smeets, Kim De Mets, Nathalie Lettens, An Sools, Sigrid Steegmans, Karen Joosten, Christel Janssens, Lieve Valkeneers, Els Goossens, Ria Hulsbosch, Valentina Butoescu, Ann Ventriglia and administrative staff: Marina Devis, Simon Maebe. We acknowledge the members of the data and safety monitoring board: Geert Robaeys, Carla Truyers, Willem Oosterlinck, Dirk Vanden Berghe and the staff of the Vesalius Research Centrum, Diether Lambrechts and Gilian Peuteman.

\section{Author details}

'Department of General Practice, University of Leuven, ACHG-KU Leuven, Kapucijnenvoer 33, Blok J, bus 7001, 3000 Leuven, Belgium. ${ }^{2}$ Unit of Urologic and Genetic Epidemiology, University of Birmingham, Birmingham, UK. ${ }^{3}$ Universiteit Maastricht, Maastricht, The Netherlands. ${ }^{4}$ Department of Urology, UZ Leuven, Leuven, Belgium. ${ }^{5}$ Department of Urology, SintElisabethziekenhuis, Turnhout, Belgium. ${ }^{6}$ Department of Urology, AZ Maria Middelares, Ghent, Belgium. 'Department of Urology, AZ Groeninge, Kortrijk, Kortrijk, Belgium. ${ }^{8}$ Department of Urology, UZ Brussel, Brussel, Belgium. ${ }^{9}$ Department of Urology, Heilig Hart ziekenhuis, Leuven, Belgium. ${ }^{10}$ Department of Urology, AZ Damiaan, Oostende, Belgium. ${ }^{11}$ Department of Urology, Jessa ziekenhuis, Hasselt, Belgium. ${ }^{12}$ Department of Urology, Kliniek Sint-Jan, Brussel, Belgium. ${ }^{13}$ Leuven University Centre for Cancer Prevention (LUCK), Department of Urology, Cliniques universitaires Saint-Luc, Brussel, Belgium. ${ }^{14}$ ACHG-KULeuven, Kapucijnenvoer 33 - Blok J - bus 7001, 3000 Leuven, Belgium.

\section{Authors' contributions}

MG: study design, conception and design of the article, analysis and interpretation of data, drafting the article. FB: study design, conception and design of the article, analysis and interpretation of data, drafting the article. SJ: study design, revising the article critically for important intellectual content. KA: local investigator, recruitment of patients, revising the article critically for important intellectual content. FA: local investigator, recruitment of patients, revising the article critically for important intellectual content. IB: local investigator, recruitment of patients, revising the article critically for important intellectual content. JB: local investigator, recruitment of patients, revising the article critically for important intellectual content. AB: local investigator, recruitment of patients, revising the article critically for important intellectual content. JD: local investigator, recruitment of patients, revising the article critically for important intellectual content. KD: local investigator, recruitment of patients, revising the article critically for important intellectual content. LG: local investigator, recruitment of patients, revising the article critically for important intellectual content. EK: study design, revising the article critically for important intellectual content. BT: local investigator, recruitment of patients, revising the article critically for important intellectual content. SV: recruitment of patients, revising the article critically for important intellectual content. BV: recruitment of patients, revising the article critically for important intellectual content. FV: local investigator, recruitment of patients, revising the article critically for important intellectual content. KV: local investigator, recruitment of patients, revising the article critically for important intellectual content. HV: study design, revising the article critically for important intellectual content. MZ: study design, conception and design of the article, analysis and interpretation of data, drafting the article. All authors read and approved the final manuscript.

\section{Conflict of interests}

The authors declare that they have no competing interests.

Received: 12 February 2012 Accepted: 21 March 2012

Published: 21 March 2012

\section{References}

1. Cancer incidence in Belgium, 2008. Belgium Cancer registry, Brussels 2011 [http://kankerregister.nettools.be/media/docs/StK_publicatie.pdf].

2. Ferlay J, Shin H, Bray F, Forman D, Mathers C, Parkin D: GLOBOCAN 2008, Cancer Incidence and Mortality Worldwide: IARC CancerBase No. 10 [Internet]. Lyon, France: International Agency for Research on Cancer 2010 [http://globocan.iarc.fr].
3. Botteman MF, Pashos CL, Redaelli A, Laskin B, Hauser R: The health economics of bladder cancer: a comprehensive review of the published literature. Pharmacoeconomics 2003, 21:1315-1330.

4. Rayman MP, Infante HG, Sargent M: Food-chain selenium and human health: emphasis on intake. Br J Nutr 2008, 100:238-253.

5. Whanger PD: Selenocompounds in plants and animals and their biological significance. J Am Coll Nutr 2002, 21:223-232.

6. Combs GF Jr, Gray WP: Chemopreventive agents: selenium. Pharmacol Ther 1998, 79:179-192.

7. Sanmartin C, Plano D, Palop JA: Selenium compounds and apoptotic modulation: a new perspective in cancer therapy. Mini Rev Med Chem 2008, 8:1020-1031.

8. Brozmanova J, Manikova D, VIckova V, Chovanec M: Selenium: a doubleedged sword for defense and offence in cancer. Arch Toxicol 2010, 84:919-938,

9. Naithani R: Organoselenium compounds in cancer chemoprevention. Mini Rev Med Chem 2008, 8:657-668.

10. Kellen E, Zeegers M, Buntinx F: Selenium is inversely associated with bladder cancer risk: a report from the Belgian case-control study on bladder cancer. Int J Urol 2006, 13:1180-1184.

11. Torun M, Aldemir H, Yardim S: Serum selenium levels in various cancer types. Trace Elements and Electrocytes 1995, 12:186-190.

12. Yalcin $\mathrm{O}$, Karatas F, Erulas FA, Ozdemir E: The levels of glutathione peroxidase, vitamin $A, E, C$ and lipid peroxidation in patients with transitional cell carcinoma of the bladder. BJU Int 2004, 93:863-866.

13. Nomura A, Heilbrun LK, Morris JS, Stemmermann GN: Serum selenium and the risk of cancer, by specific sites: case-control analysis of prospective data. J Natl Cancer Inst 1987, 79:103-108.

14. Helzlsouer KJ, Comstock GW, Morris JS: Selenium, lycopene, alphatocopherol, beta-carotene, retinol, and subsequent bladder cancer. Cancer Res 1989, 49:6144-6148.

15. Zeegers MP, Goldbohm RA, Bode P, van den Brandt PA: Prediagnostic toenail selenium and risk of bladder cancer. Cancer Epidemiol Biomarkers Prev 2002, 11:1292-1297.

16. Michaud DS, Hartman TJ, Taylor PR, Pietinen P, Alfthan G, Virtamo J, Albanes D: No Association between toenail selenium levels and bladder cancer risk. Cancer Epidemiol Biomarkers Prev 2002, 11:1505-1506.

17. Michaud DS, De Vivo I, Morris JS, Giovannucci E: Toenail selenium concentrations and bladder cancer risk in women and men. $\mathrm{Br} J$ Cancer 2005, 93:804-806.

18. Dennert G, Zwahlen M, Brinkman M, Vinceti M, Zeegers Maurice PA, Horneber M: Selenium for preventing cancer. Book Selenium for preventing cancer City: John Wiley \& Sons, Ltd; 2011, (Editor ed.^eds.).

19. Rayman MP: The use of high-selenium yeast to raise selenium status: how does it measure up? Br J Nutr 2004, 92:557-573.

20. Duffield-Lillico AJ, Dalkin BL, Reid ME, Turnbull BW, Slate EH, Jacobs ET, Marshall JR, Clark LC: Selenium supplementation, baseline plasma selenium status and incidence of prostate cancer: an analysis of the complete treatment period of the Nutritional Prevention of Cancer Trial. BJU Int 2003, 91:608-612.

21. Lippman SM, Klein EA, Goodman PJ, Lucia MS, Thompson IM, Ford LG, Parnes HL, Minasian LM, Gaziano JM, Hartline JA, et al: Effect of selenium and vitamin $\mathrm{E}$ on risk of prostate cancer and other cancers: the Selenium and Vitamin E Cancer Prevention Trial (SELECT). JAMA 2009, 301:39-51.

22. Goossens ME, Buntinx F, Zeegers MP: Re: Selenium and vitamin E: interesting biology and dashed hope. J Natl Cancer Inst 2009, 101:1363-1364, author reply 1364 .

23. Brinkman M, Buntinx F, Muls E, Zeegers MP: Use of selenium in chemoprevention of bladder cancer. Lancet Oncol 2006, 7:766-774

24. Grossman HB, Stenzl A, Moyad MA, Droller MJ: Bladder cancer: Chemoprevention, complementary approaches and budgetary considerations. Scand J Urol Nephrol 2008, 42:213-233.

25. Altwein JE: [Primary prevention of bladder cancer. What's new?]. Urologe A 2007, 46:616-621.

26. Busby JE, Kamat AM: Chemoprevention for bladder cancer. J Urol 2006, 176:1914-1920.

27. Amaral AF, Cantor KP, Silverman DT, Malats N: Selenium and bladder cancer risk: a meta-analysis. Cancer Epidemiol Biomarkers Prev 2010, 19:2407-2415. 
28. Hatfield DL, Gladyshev VN: The Outcome of Selenium and Vitamin E Cancer Prevention Trial (SELECT) reveals the need for better understanding of selenium biology. Mol Interv 2009, 9:18-21.

29. Larsen EH, Hansen M, Paulin H, Moesgaard S, Reid M, Rayman M: Speciation and bioavailability of selenium in yeast-based intervention agents used in cancer chemoprevention studies. J AOAC Int 2004, 87:225-232.

30. Oosterlinck W: Guidelines on diagnosis and treatment of superficial bladder cancer. Minerva Urol Nefrol 2004, 56:65-72.

31. Navarro-Alarcon M, Cabrera-Vique C: Selenium in food and the human body: a review. Sci Total Environ 2008, 400:115-141.

32. MacFarquhar JK, Broussard DL, Melstrom P, Hutchinson R, Wolkin A, Martin C, Burk RF, Dunn JR, Green AL, Hammond R, et al: Acute selenium toxicity associated with a dietary supplement. Arch Intern Med 2010, 170:256-261.

33. Yang G, Zhou R, Yin S, Gu L, Yan B, Liu Y, Li X: Studies of safe maximal daily dietary selenium intake in a seleniferous area in China I. Selenium intake and tissue selenium levels of the inhabitants. J Trace Elem Electrolytes Health Dis 1989, 3:77-87.

34. Food: and Nutrition Board - USA Institute of Medicine: Dietary References Intakes for Vitamin C, Vitamin E, Selenium and Carotenoids. Washington: National Academy Press; 2000.

35. Malmstrom PU, Sylvester RJ, Crawford DE, Friedrich M, Krege S, Rintala E, Solsona E, Di Stasi SM, Witjes JA: An individual patient data meta-analysis of the long-term outcome of randomised studies comparing intravesical mitomycin C versus bacillus Calmette-Guerin for non-muscle-invasive bladder cancer. Eur Urol 2009, 56:247-256.

36. Ashughyan VR, Marihart S, Djavan B: Chemopreventive trials in urologic cancer. Rev Urol 2006, 8:8-13.

37. Lamm DL, Riggs DR, Shriver JS, Van Gilder PF, Rach JF, DeHaven J: Megadose vitamins in bladder cancer: a double-blind clinical trial. J Urol 1994, 151:21-26.

38. Prout GR Jr, Barton BA: 13-cis-retinoic acid in chemoprevention of superficial bladder cancer. The National Bladder Cancer Group. J Cell Biochem Supp/ 1992, 16l:148-152.

39. Sabichi AL, Lerner SP, Atkinson EN, Grossman HB, Caraway NP, Dinney CP, Penson DF, Matin S, Kamat A, Pisters LL, et al: Phase III prevention trial of fenretinide in patients with resected non-muscle-invasive bladder cancer. Clin Cancer Res 2008, 14:224-229.

40. Studer UE, Jenzer S, Biedermann C, Chollet D, Kraft R, von Toggenburg H, Vonbank F: Adjuvant treatment with a vitamin A analogue (etretinate) after transurethral resection of superficial bladder tumors. Final analysis of a prospective, randomized multicenter trial in Switzerland. Eur Urol 1995, 28:284-290.

41. Newling DW, Robinson MR, Smith PH, Byar D, Lockwood R, Stevens I, De Pauw M, Sylvester R: Tryptophan metabolites, pyridoxine (vitamin B6) and their influence on the recurrence rate of superficial bladder cancer. Results of a prospective, randomised phase III study performed by the EORTC GU Group. EORTC Genito-Urinary Tract Cancer Cooperative Group. Eur Urol 1995, 27:110-116.

42. Byar D, Blackard C: Comparisons of placebo, pyridoxine, and topical thiotepa in preventing recurrence of stage I bladder cancer. Urology 1977, 10:556-561.

43. Messing E, Kim KM, Sharkey F, Schultz M, Parnes H, Kim D, Saltzstein D, Wilding G: Randomized prospective phase III trial of difluoromethylornithine vs placebo in preventing recurrence of completely resected low risk superficial bladder cancer. J Urol 2006, 176:500-504.

44. Naito S, Koga H, Yamaguchi A, Fujimoto N, Hasui Y, Kuramoto H, Iguchi A, Kinukawa N: Prevention of recurrence with epirubicin and lactobacillus casei after transurethral resection of bladder cancer. J Urol 2008, 179:485-490.

45. Aso Y, Akaza H, Kotake T, Tsukamoto T, Imai K, Naito S: Preventive effect of a Lactobacillus casei preparation on the recurrence of superficial bladder cancer in a double-blind trial. The BLP Study Group. Eur Urol 1995, 27:104-109.

46. Zeegers MP, Bryan RT, Langford C, Billingham L, Murray P, Deshmukh NS, Hussain S, James N, Wallace DM, Cheng KK: The West Midlands Bladder Cancer Prognosis Programme: rationale and design. BJU Int 2009, 105:784-788
47. Stratton MS, Reid ME, Schwartzberg G, Minter FE, Monroe BK, Alberts DS, Marshall JR, Ahmann FR: Selenium and inhibition of disease progression in men diagnosed with prostate carcinoma: study design and baseline characteristics of the 'Watchful Waiting' Study. Anticancer Drugs 2003, 14:595-600

48. Stranges S, Marshall JR, Trevisan M, Natarajan R, Donahue RP, Combs GF, Farinaro E, Clark LC, Reid ME: Effects of selenium supplementation on cardiovascular disease incidence and mortality: secondary analyses in a randomized clinical trial. Am J Epidemiol 2006, 163:694-699.

49. Stranges S, Marshall JR, Natarajan R, Donahue RP, Trevisan M, Combs GF, Cappuccio FP, Ceriello A, Reid ME: Effects of long-term selenium supplementation on the incidence of type 2 diabetes: a randomized trial. Ann Intern Med 2007, 147:217-223.

50. Algotar AM, Stratton MS, Stratton SP, Hsu CH, Ahmann FR: No effect of selenium supplementation on serum glucose levels in men with prostate cancer. Am J Med 2010, 123:765-768.

51. Laclaustra M, Navas-Acien A, Stranges S, Ordovas JM, Guallar E: Serum selenium concentrations and diabetes in U.S. adults: National Health and Nutrition Examination Survey (NHANES) 2003-2004. Environ Health Perspect 2009, 117:1409-1413.

52. MacKenzie T, Zens MS, Ferrara A, Schned A, Karagas MR: Diabetes and risk of bladder cancer: evidence from a case-control study in New England. Cancer 2011, 117:1552-1556.

53. Yang KC, Lee LT, Lee YS, Huang HY, Chen CY, Huang KC: Serum selenium concentration is associated with metabolic factors in the elderly: a cross-sectional study. Nutr Metab (Lond) 2010, 7:38.

54. Stranges S, Navas-Acien A, Rayman MP, Guallar E: Selenium status and cardiometabolic health: state of the evidence. Nutr Metab Cardiovasc Dis 2010, 20:754-760.

55. Laclaustra M, Navas-Acien A, Stranges S, Ordovas JM, Guallar E: Serum selenium concentrations and hypertension in the US Population. Circ Cardiovasc Qual Outcomes 2009, 2:369-376.

56. Nawrot TS, Staessen JA, Roels HA, Den Hond E, Thijs L, Fagard RH, Dominiczak AF, Struijker-Boudier HA: Blood pressure and blood selenium: a cross-sectional and longitudinal population study. Eur Heart J 2007, 28:628-633.

57. Rayman MP: Selenoproteins and human health: insights from epidemiological data. Biochim Biophys Acta 2009, 1790:1533-1540.

58. Yang GQ, Xia YM: Studies on human dietary requirements and safe range of dietary intakes of selenium in China and their application in the prevention of related endemic diseases. Biomed Environ Sci 1995, 8:187-201.

59. Kellen E, Zeegers MP, Dirx M, Houterman S, Droste J, Lawrence G, Truyers C, Bruckers L, Molenberghs G, Joniau S, Buntinx F: Occurrence of both bladder and prostate cancer in five cancer registries in Belgium, The Netherlands and the United Kingdom. Eur J Cancer 2007, 43:1694-1700.

60. Kellen E, Zeegers MP, Joniau S, Buntinx F: Examining the co-occurrence of bladder and prostate cancer: a worthwhile investigation? Future Oncol 2007, 3:515-519.

\section{Pre-publication history}

The pre-publication history for this paper can be accessed here: http://www.biomedcentral.com/1471-2490/12/8/prepub

\section{doi:10.1186/1471-2490-12-8}

Cite this article as: Goossens et al:: Designing the selenium and bladder cancer trial (SELEBLAT), a phase III randomized chemoprevention study with selenium on recurrence of bladder cancer in Belgium. BMC Urology 2012 12:8. 